\title{
Yeşil Mercimek (Lens culinaris Medik.) Çeşitlerinde Farklı Priming Uygulamalarının Çimlenme ve Fide Gelişimi Üzerine Etkileri
}

\section{Effects of Different Priming Techniques on Germination and Seedling Growth of Green Lentil (Lens culinaris Medik.)} Cultivars

\author{
Özge Doğanay Erbaş Köse ${ }^{1 *}$, Yusuf Murat Kardeş ${ }^{1}$, Murat Karaer ${ }^{2}$, Zeki Mut ${ }^{1}$
}

Geliş / Received: 21/08/2019

Revize / Revised: 06/09/2019

Kabul / Accepted: 08/09/2019

$\ddot{O}$

z- Mercimek insan gıdası ve hayvan yemi olarak kullanılan ve toprak verimliliğini arttıran çok önemli bir yemeklik tane baklagil bitkisidir. Kurak bölgelerde mercimeğin çimlenme ve fide gelişimi verimi etkileyen en önemli faktörlerden birisidir. Mercimek tarımında yüksek verim için bölgeye uygun yüksek verimli çeşitlerin seçiminin yanında, yetiştirme tekniklerinin de iyileştirilmesi diğer önemli bir yöntemdir. Son yıllarda üzerinde durulan konulardan birisi ekim öncesi tohum uygulamaları (priming) dır. Yeşil mercimek çeşitlerinde farklı priming uygulamalarının çimlenme özellikleri ile fide gelişimi üzerine etkisinin araştırıldığı bu çalışma; kontrollü bitki büyütme odasında iki kışılı (Ankara Yeşili ve Ceren), bir yazlık (Sultan) ve bir yerel olmak üzere 4 yeşil mercimek genotipi ile 2019 yılında yürütülmüştür. Araştırmada kullanılan çeşitlerin tohumları ekimden önce; priming uygulamasız, saf su, gibberellik asit (50 ve 100 ppm), hümik asit (2000 ve 4000 ppm) ile muamele edilmiştir.

Sonuç olarak, mercimek çeşitlerinin tohumlarına farklı ön uygulamalar yapılarak yürütülen çalışmada uygulanan bütün ön uygulamaların kontrole göre çimlenme oranını arttırdığı belirlenmiştir. Gibberellik asit dozlarının sürgün uzunluğu, hümik asit dozlarının ise kök uzunluğu artışında daha etkili olduğu belirlenmiştir. Priming uygulamalarının incelenen çimlenme ve fide özelliklerine genellikle olumlu etki ettiği belirlenmiştir.

Anahtar Kelimeler: Mercimek, Genotip, Priming, Çimlenme, Fide

$A$ bstract- Lentil is a very important edible legume plant used for human food and animal feed. Germination and seedling development of lentils in arid regions is one of the most important factors determining yield. In lentil farming, besides the selection of yielding cultivars suitable for that region, improvement of agricultural practices and methods are highly effective for high yield. One of these practices is the pre-sowing seed applications (priming) which have been focused on in recent years.

This study was conducted to investigate the effect of different priming treatments on germination characteristics and seedling growth of green lentil varieties. The study was carried out in 2019 in a controlled plant growing room with 4 green lentil genotypes: two winter cultivars (Ankara Yeşili and Ceren), one spring cultivar (Sultan) and one local genotype. Seeds were primed with control, pure water, gibberellic acid 50 ppm, gibberellic acid $100 \mathrm{ppm}$, humic acid $2000 \mathrm{ppm}$ and humic acid $4000 \mathrm{ppm}$ before planting. As a result, it was determined that all pretreatments applied to the lentil cultivars increased germination rate compared to control. It was determined that gibberellic acid doses were more effective on shoot length and humic acid doses were more effective on root length. Priming applications generally had a positive effect on the germination criteria examined.

Keywords: Lentil, Genotype, Priming, Germination, Seedling 


\section{GİRIŞ}

Dünya'da mercimek 6.6 milyon ha alanda ekilmekte ve bu alandan 7.6 milyon ton ürün elde edilmektedir. Türkiye'de ise mercimek 277 bin ha alanda ekilmekte olup, bu alandan 353 bin ton ürün alınmaktadır [1,2]. Türkiye'de toplam mercimek üretiminin sadece \% 12.1'lik (43 bin ton) kısmını yeşil mercimek olușturmaktadır. Mercimek (Lens culinaris Medik.) sulanmadan yetiștirilebilen ve kuraklığa dayanıklı önemli yemeklik baklagillerden biridir [3]. Mercimek, yağışın sadece düşük olduğu değil aynı zamanda değişken olduğu Türkiye'nin İç Anadolu bölgesi ve geçit bölgelerinde de yetişen önemli bir baklagildir. Mercimek tarımının yapıldığı alanlardaki topraklarda kaymak tabakasının oluşması, suyun sınırlı olması, toprak organik maddesinin düşük olması ve tuzluluk gibi önemli abiyotik stresler tek tek veya birlikte çimlenmeyi olumsuz yönde etkileyebilmektedir. Kurak ve yarı kurak bölgelerde, çimlenme için gereken su kısıtlı olduğundan, başarılı bir yetiştiricilik için çimlenme kabiliyeti yüksek, hızlı ve homojen çimlenebilen tohumlar gerekmektedir $[4,5]$. Çimlenme ve fide gelişimi bitki yaşam döngüsünün kritik safhalarındandır [6]. Özellikle olumsuz çevresel koşullar altında verimi arttırmak için farklı teknikler kullanılabilir. Sağlıklı fide oluşumu ve verimi arttırabilecek basit tekniklerden biri de tohum ön uygulamaları (priming) dır [7, 8]. Priming, kökçük çıkışı hariç metabolizmayı başlatacak kadar bir dizi kimyasal olayların gerçekleşmesi için tohumun kimyasal bir bileşikle, herhangi bir enerji formuyla veya slatma, kurutma gibi işlemler ile muamele edilmesi işlemidir [9-11]. Priming ile tohum kabuğu yüzeyinin daha geçirgen hale gelmesi sağlanmaktadır [12,13]. Yapılan çalışmalarda çimlenme oranının arttırılması, üniform büyüme ve güçlü fide gelişiminin ön uygulamalarla sağlanarak, tohumun tarla performansını arttırabileceği bildirilmiştir [14-16]. Ön uygulama işleminin en basit tekniklerinden biri DNA ve RNA sentezini, alfa amilaz aktivitelerini ve daha iyi embriyo büyümesini sağlayan su ile ön uygulama (hidropriming) işlemidir [17].

Yeşil mercimek'in yabancı otlara rekabetinin zayıf olması, hastalıklara hassas olması, sertifikalı tohumluk bulunamaması veya kullanımının yaygın olmaması, çıkısın az olması yetiştiriciliğinin azalmasının temel nedenlerindendir [18]. Çalışmada kullandığımız, gibberallik asit, bitki büyüme ve gelişmesinde, dormansinin ortadan kaldırılmasında, çimlenmenin kontrolü ve uyarılmasında etkili olan önemli bir bitki hormonudur [19]. Hümik asit ise bitki fizyolojisi, bitki gelişimi ve beslenmesi üzerine olumlu ve tuzluluğa dayanımı arttıran organik bir maddedir [20,21]. Bu çalışmada, dört farklı yeşil mercimek çeşidine beş farklı ön uygulamanın (saf su, Gibberelik asit (50 ve 100 ppm), Hümik asit (2000 ve 4000 ppm)) çimlenme ve fide gelişimi üzerine etkileri incelenmiştir.

\section{MATERYAL VE METOT}

Bu çalışma, Bilecik Şeyh Edebali Üniversitesi Ziraat ve Doğa Bilimleri Fakültesi, Tarımsal Uygulama ve Araştırma Merkezi bünyesinde bulunan iklimlendirme odasında yürütülmüştür. Çalışmada aynı yıl üretilen ve aynı depolarda saklanan iki kışlık (Ankara Yeşili ve Ceren), bir yazlık (Sultan) ve bir yerel olmak üzere 4 yeşil mercimek genotipi kullanılmıştır. Tohumlar \% 5'lik Sodyum hipoklorit çözeltisi ile 30 dakika yüzey sterilizasyonuna tabi tutulmuş ve ardından saf suyla birkaç defa yıkanmıştır. Ön uygulama (priming) olarak; saf su, gibberellic acid (GA), hümik asit (HA) kullanılmıştır. Denemede kullanılmak üzere kontrol ile birlikte saf su, $\mathrm{GA}_{1}(50 \mathrm{ppm}), \mathrm{GA}_{2}(100 \mathrm{ppm}), \mathrm{HA}_{1}(2000 \mathrm{ppm}), \mathrm{HA}_{2}(4000 \mathrm{ppm})$ dozları hazırlanmış ve tohumlar 24 saat bu sıvılarda bekletilmiştir. Daha sonra saf su ile üç kez yıkanmış tohumlar oda sıcaklığında 24 saat havlu kağıtlar üzerinde kurutulmuştur. Kurutulmuş tohumlardan her çeşit için uygulanan işlemlerden ayrı ayrı 30 tohum sayılmış ve bu tohumlar iki filtre kağıdının üzerine plastik büyütme kaplarına yerleştirilmişlerdir. Her kaba 15 $\mathrm{ml}$ saf su ilave edilmiştir. Buharlaşmayı önlemek için kaplar kilitli torbalar içerisine yerleştirilmiştir [22]. Hazırlanan uygulamalar kontrollü şartlarda $20{ }^{\circ} \mathrm{C}$ oda sıcaklığında karanlık ortamda faktöriyel düzenlemede tesadüf parselleri deneme desenine göre 4 tekrarlı olarak kurulmuştur. Çimlenme kriteri olarak 2 mm'lik kökçük çıkışı kabul edilmiş ve 10 gün boyunca sayımlara devam edilmiştir. Onuncu günün sonunda çimlenme yüzdesi, sürgün uzunluğu, kök uzunluğu, sürgün yaş ve kuru ağırlığı, kök yaş ve kuru ağırlığı belirlenmiştir [19]. Elde edilen veriler MSTAT-C paket programı kullanılarak analiz edilmiştir, farklılık gruplandırılması Duncan testine göre yapılmıştır.

\section{BULGULAR VE TARTIȘMA}

Çalışmada incelenen bütün özellikler için; çeşit, doz ve çeşit $\times$ doz interaksiyonları istatistiki olarak önemli bulunmuş ve işlemlere ait gruplandırmalar ve ortalama değerler Tablo 1 ve Tablo 2'de verilmiştir.

Çeşitler arasında en yüksek çimlenme oranı \% 88.09 ile Ceren çeşidinden, en düşük çimlenme oranı ise \% 77.16 ile yerel genotipden elde edilmiştir. Uygulanan dozlara göre çimlenme oranı \% 72.52 (Kontrol) ile $89.35\left(\mathrm{HA}_{2}\right)$ arasında değişmiştir. Çimlenme yüzdesi en yüksek $\mathrm{HA}_{2}$ 'den elde edilmiş ve bunu sırasıyla saf su 
(\% 85.08), $\mathrm{HA}_{1}$ (\% 83.72), $\mathrm{GA}_{2}$ (\% 80.80), $\mathrm{GA}_{1}$ (\% 79.45) ve kontrol (\% 72.52) dozları takip etmiştir (Tablo 1, Şekil 1). Priming uygulaması çimlenme oranını kontrole göre $\mathrm{HA}_{2}$ uygulamasında \% 23.2, saf su uygulamasında $\% 17.3$ oranında arttırmıştır. Çeşit $\times$ doz interaksiyonunda çimlenme oranı en düşük \% 67.33 ile Sultan çeşidinin Kontrol uygulamasında, en yüksek \% 93.80 ile Ceren çeşidinin $\mathrm{HA}_{2}$ uygulamasında elde edilmiştir (Tablo 2). Ön uygulama yapılan bütün tohumlar kontrole göre daha yüksek çimlenme oranına sahip olmuştur. Yapılan çalışmalarda hümik asit'in bitki fizyolojisi, bitki gelişimi ve beslenmesi üzerine olumlu etkileri olduğu [20, 23] ve tuzluluğa dayanımı arttırdığı belirlenmiştir [5, 21, 24]. Türkmen ve ark [25]'nın domates bitkisinde humik asit uygulamasının çimlenme üzerine olumlu etki gösterdiğini, Westwood [26] gibberellik asitlerin tohumlarda dormansiyi kırarak çimlenmeyi arttırdığını, Yamaguchi ve Kamiya [29] gibberellinlerin enzimleri etkileyerek çimlenmeyi arttırdığını, Çokkızgın [22] ise üç bezelye çeşidinde yaptığı çalışmada hidro priming uygulamasının çimlenmeyi arttırdığını bildirmiştir. Yemeklik tane baklagillerde çıkış oranının düşük olması verimin azalmasına neden olan temel faktörlerdendir [18]. Ön uygulamaların çimlenmeyi başlatacak dereceye kadar (kökçük çıkısı hariç) tohumun içine su alınımını sağladığından $[12,28]$ çimlenme oranını arttırdığı ve daha güçlü fideler elde edildiği [11] bildirilmiştir.

Ele alınan çeşitler arasında Ceren $5.13 \mathrm{~cm}$ ile en yüksek sürgün uzunluğuna sahip olmuştur. Farklı uygulamalarda elde edilen sürgün uzunluğuna ilişkin ortalamalar incelendiğinde ise kontrol uygulamasında 3.75 $\mathrm{cm}$ olan sürgün uzunluğunun $\mathrm{GA}_{2}$ uygulamasında $5.40 \mathrm{~cm}$ ' e yükseldiği belirlenmiştir (Tablo 1). Çeşit $\times$ doz interaksiyonuna göre en uzun sürgün uzunluğuna $6.49 \mathrm{~cm}$ ile Ceren çeşidinin $\mathrm{GA}_{2}$ dozundan elde edilmiş ve bu interaksiyonla 5.99 ile Ceren çeşidinin $\mathrm{GA}_{1}$ uygulaması aynı istatistiki grupta yer almıştır (Tablo 2). Hümik maddelerin çimlenme sürecinde sürgün büyümesini arttırdı̆̆ 15,29$]$ gibberellinlerin ise hücre büyüme ve bölünmelerini arttırarak boy ve boğum aralarının dolayısıyla sürgünlerin uzun olmasına neden olduğu [30] bildirilmiştir.

Çeşitler ve priming uygulamaları kök uzunluğunu önemli derece etkilemiştir. Kök uzunluğu bakımından çeşitler arasında istatistiki olarak önemli fark belirlenmiş ve $5.10 \mathrm{~cm}$ ile en yüksek Sultan çeşidinde en düşük ise $3.73 \mathrm{~cm}$ ile yerel mercimek çeşidinde ölçülmüştür. Uygulamalar arasında da kök uzunluğu bakımından istatistiki olarak önemli fark belirlenmiş olup, sırasıyla $\mathrm{HA}_{2}(5.17 \mathrm{~cm}), \mathrm{HA}_{1}(4.92 \mathrm{~cm}), \mathrm{GA}_{2}(4.77$ $\mathrm{cm}), \mathrm{GA}_{1}(4.33 \mathrm{~cm})$, saf su $(4.07 \mathrm{~cm})$ ve kontrol $(3.27 \mathrm{~cm})$ uygulamalarından elde edilmiştir. Kök uzunluğu bakımından yapılan bütün uygulamalar kontrole göre daha yüksek değerler göstermiştir (Tablo 1, Şekil 1). Çeşitlerin değişen uygulamalardaki durumları incelendiğinde en kısa kök uzunluğu $2.47 \mathrm{~cm}$ ile yerel genotipten Kontrol uygulamasında, en uzun $6.05 \mathrm{~cm}$ ile Sultan çeşidinden $\mathrm{HA}_{2}$ uygulamasında elde edilmiştir (Tablo 2). Yapılan çalışmalarda kök uzamasına ön uygulamalardan hümik maddelerin [5] ve gibberellinlerin [30- 32] olumlu etki ettiği bildirmiştir. Birçok araştırıcı tohum ön uygulamaların uygulanan yönteme göre kök uzunluğuna farklı derecede olmak üzere çoğunlukla olumlu etki gösterdiğini bildirmişlerdir [33-36]. 
Tablo 1. Çalışmada kullanılan mercimek çeşitleri ve dozlara ait ortalama çimlenme oranı, sürgün ve fide özellikleri*

\begin{tabular}{|c|c|c|c|c|c|c|c|}
\hline & \multirow[b]{2}{*}{$\begin{array}{l}\text { Çimlenme } \\
\text { Oranı (\%) }\end{array}$} & \multirow[b]{2}{*}{$\begin{array}{l}\text { Sürgün Uzunluğu } \\
(\mathbf{c m})\end{array}$} & \multirow[b]{2}{*}{$\begin{array}{c}\text { Kök Uzunluğu } \\
\text { (cm) }\end{array}$} & \multicolumn{2}{|c|}{ Sürgün (mg bitki-1) } & \multicolumn{2}{|c|}{ Kök (mg bitki $\left.{ }^{-1}\right)$} \\
\hline & & & & $\begin{array}{l}\text { Yaş } \\
\text { A ğırlık }\end{array}$ & $\begin{array}{l}\text { Kuru } \\
\text { Ağırlık }\end{array}$ & $\begin{array}{l}\text { Yaş } \\
\text { Ağırlık }\end{array}$ & $\begin{array}{l}\text { Kuru } \\
\text { Ağırlık }\end{array}$ \\
\hline \multicolumn{8}{|l|}{ Çeşitler } \\
\hline Ankara Yeşili & $79.33 \mathrm{c}$ & $3.61 \mathrm{c}$ & $4.64 \mathrm{~b}$ & $40.97 \mathrm{bc}$ & $3.27 \mathrm{~b}$ & $33.63 \mathrm{~b}$ & $2.79 \mathrm{~b}$ \\
\hline Ceren & $88.09 \mathrm{a}$ & $5.13 \mathrm{a}$ & $4.21 \mathrm{c}$ & $39.89 \mathrm{~b}$ & $3.39 \mathrm{~b}$ & $35.85 \mathrm{~b}$ & $2.99 \mathrm{a}$ \\
\hline Sultan & $82.70 \mathrm{~b}$ & $4.43 \mathrm{~b}$ & $5.10 \mathrm{a}$ & $49.51 \mathrm{a}$ & $4.38 \mathrm{a}$ & $43.51 \mathrm{a}$ & $3.00 \mathrm{a}$ \\
\hline Yerel & $77.16 \mathrm{~d}$ & $4.33 \mathrm{~b}$ & $3.73 \mathrm{~d}$ & $35.18 \mathrm{c}$ & $3.38 \mathrm{~b}$ & $31.07 \mathrm{c}$ & $2.81 \mathrm{~b}$ \\
\hline \multicolumn{8}{|l|}{ Dozlar } \\
\hline Kontrol & $72.52 \mathrm{~d}$ & $3.75 \mathrm{~d}$ & $3.27 \mathrm{~d}$ & $42.50 \mathrm{bc}$ & $2.90 \mathrm{c}$ & $37.05 \mathrm{~b}$ & $2.37 \mathrm{c}$ \\
\hline Saf su & $85.08 \mathrm{~b}$ & $3.77 \mathrm{~d}$ & $4.07 \mathrm{c}$ & $46.85 \mathrm{a}$ & $3.82 \mathrm{ab}$ & $43.22 \mathrm{a}$ & $3.65 \mathrm{a}$ \\
\hline $\mathrm{GA}_{1}$ & $79.45 \mathrm{c}$ & $4.90 \mathrm{~b}$ & $4.33 \mathrm{c}$ & $34.45 \mathrm{c}$ & $3.46 \mathrm{bc}$ & $31.79 \mathrm{~d}$ & $2.52 \mathrm{bc}$ \\
\hline $\mathrm{GA}_{2}$ & $80.80 \mathrm{c}$ & $5.40 \mathrm{a}$ & $4.77 \mathrm{~b}$ & $36.75 \mathrm{c}$ & $3.78 \mathrm{~b}$ & $31.79 \mathrm{~d}$ & $2.78 \mathrm{~b}$ \\
\hline $\mathrm{HA}_{1}$ & $83.72 b$ & $4.33 \mathrm{c}$ & $4.92 \mathrm{ab}$ & $42.17 \mathrm{bc}$ & $3.75 \mathrm{~b}$ & $33.85 \mathrm{c}$ & $2.70 \mathrm{bc}$ \\
\hline $\mathrm{HA}_{2}$ & $89.35 \mathrm{a}$ & $4.11 \mathrm{c}$ & $5.17 \mathrm{a}$ & $45.58 \mathrm{ab}$ & $3.92 \mathrm{a}$ & $38.39 \mathrm{~b}$ & $3.35 \mathrm{a}$ \\
\hline
\end{tabular}

$\mathrm{GA}_{1}$ : $50 \mathrm{ppm}, \mathrm{GA}_{2}: 100 \mathrm{ppm}, \mathrm{HA}_{1}: 2000 \mathrm{ppm}, \mathrm{HA}_{2}: 4000 \mathrm{ppm}$, * Her sütunda aynı harfle gösterilen ortalamalar arasında 0.01 önem düzeyine göre fark yoktur.

Çeşitler arasında en fazla yaş ve kuru sürgün ağırlı̆̆ı (sırasıyla 49.51 ve 4.38 mg bitki ${ }^{-1}$ ) Sultan çeşidinden elde edilmiştir. Uygulanan dozlar arasında en fazla yaş sürgün ağırlığı $46.85 \mathrm{mg} \mathrm{bitki}^{-1}$ ile Saf su uygulamasından elde edilmiş, $\mathrm{HA}_{2}$ dozu $\left(45.58 \mathrm{mg}^{\text {bitki }}{ }^{-1}\right)$ saf su uygulaması ile aynı istatistiki grupta yer almıştır. En fazla kuru sürgün ağırlığ 1 ise $\mathrm{HA}_{2}\left(3.92 \mathrm{mg}\right.$ bitki $\left.{ }^{-1}\right)$ ve saf su (3.82 mg bitki $\left.{ }^{-1}\right)$ uygulamasından elde edilmiştir (Tablo 1, Şekil 1). Çeşit $\times$ doz interaksiyonu incelendiğinde yaş sürgün ağırlığı en az $25.95 \mathrm{mg} \mathrm{bitki}^{-1}$ ile Yerel genotipin $\mathrm{GA}_{1}$ uygulamasından, en fazla ise $57.60 \mathrm{mg} \mathrm{bitki}^{-1}$ ile Sultan çeşidinin saf su uygulamasından elde edilmiştir. Kuru Sürgün ağırlığı en az $2.58 \mathrm{mg}_{\text {bitki }}{ }^{-1}$ ile Ceren çeşidinin kontrol uygulamasında, en fazla $5.39 \mathrm{mg} \mathrm{bitki}^{-1}$ ile Sultan çeşidinin saf su uygulamasında elde edilmiştir (Tablo 2). Farklı bitkilerde yapılan çalışmalarda ön uygulamaların yaş ve kuru sürgün ağırlığını kontrole göre arttırdığı bildirilmiştir [19, 31, 32, 3739].

Çalışmada kullanılan çeşitler arasında en fazla kök yaş ve kuru ağırlığına (sırasıyla 43.51 ve $3.00 \mathrm{mg}$ bitki $^{-1}$ ) Sultan çeşidi sahip olmuştur. Ele alınan dozlar arasında en fazla kök yaş ve kuru ağırlığı sırasıyla 43.22 ve $3.65 \mathrm{mg} \mathrm{bitki}^{-1}$ ile saf su uygulamasında elde edilmiştir (Tablo 1, Şekil 1). Çeşitlerin değişen uygulamalardaki durumları incelendiğinde en fazla yaş (54.06 mg bitki $\left.{ }^{-1}\right)$ ve kuru (4.29 mg bitki $\left.{ }^{-1}\right)$ kök ağırlığı Sultan çeşidinin saf su uygulamasında elde edilmiştir. En düşük kök yaş ağırlığı $24.53 \mathrm{mg}$ bitki $^{-1}$ ile yerel genotipin $\mathrm{GA}_{1}$ uygulamasında, en az kuru kök ağırlığı ise $1.95 \mathrm{mg} \mathrm{bitki}^{-1}$ ile Ankara yeşili çeşidinin Kontrol uygulamasında elde edilmiştir (Tablo 2). Yapılan çalışmalarda yaş ve kuru kök ağırlığının uygulanan ön uygulamalara bağlı olarak azaldığ 1 [35] veya arttığ 1 [19, 32, 38, 39] belirlenmiştir. 
Özge Doğanay Erbaş Köse, Yusuf Murat Kardeş, Murat Karaer, Zeki Mut/ BŞEÜ Fen Bilimleri, 6. Cilt - Prof. Dr. Fuat SEZGİN Bilim Yılı Özel Sayısı, 247-255, 2019

Tablo 2. Mercimek çeşitlerinde tohum ön uygulamalarının çimlenme ve fide özelliklerine etkileri

\begin{tabular}{|c|c|c|c|c|c|c|c|c|c|c|c|c|c|c|c|}
\hline \multirow{3}{*}{ Çeşitler } & \multirow{3}{*}{$\begin{array}{l}\text { Uygulamalar } \\
\text { Kontrol }\end{array}$} & \multirow{2}{*}{\multicolumn{2}{|c|}{$\begin{array}{l}\text { Çimlenme } \\
\text { Oranı (\%) }\end{array}$}} & \multirow{2}{*}{\multicolumn{2}{|c|}{$\begin{array}{c}\text { Sürgün } \\
\text { Uzunluğu (cm) }\end{array}$}} & \multirow{2}{*}{\multicolumn{2}{|c|}{$\begin{array}{c}\text { Kök } \\
\text { Uzunluğu (cm) }\end{array}$}} & \multicolumn{4}{|c|}{ Sürgün $\left(\mathrm{mg}\right.$ bitki $\left.^{-1}\right)$} & \multicolumn{4}{|c|}{ Kök (mg bitki $\left.{ }^{-1}\right)$} \\
\hline & & & & & & & & \multicolumn{2}{|c|}{ Yaş Ağırlık } & \multicolumn{2}{|c|}{ Kuru Ağırlık } & \multicolumn{2}{|c|}{ Yaş Ağırlık } & \multicolumn{2}{|c|}{ Kuru Ağırlık } \\
\hline & & 70.07 & hi & $\underline{2.96}$ & $\underline{k}$ & 3.27 & $\mathrm{j}$ & 38.68 & $\mathrm{ij}$ & 2.83 & $\mathrm{ij}$ & 28.15 & $g-j$ & $\underline{1.95}$ & $i$ \\
\hline \multirow{5}{*}{ Ankara Yeşili } & Saf su & 81.27 & cde & 3.00 & $\mathrm{k}$ & 3.89 & $f-j$ & 44.93 & def & 3.35 & def & 38.06 & $\mathrm{~b}-\mathrm{e}$ & 3.03 & $\mathrm{c}-\mathrm{h}$ \\
\hline & $\mathbf{G A}_{1}$ & 73.53 & fgh & 3.59 & $\mathrm{~h}-\mathrm{k}$ & 4.26 & d-h & 33.14 & $\mathrm{kl}$ & 2.88 & hi & 28.01 & hij & 2.63 & $f-j$ \\
\hline & $\mathbf{G A}_{2}$ & 77.93 & def & 5.12 & cde & 5.40 & $\mathrm{ab}$ & 31.93 & $\mathrm{kl}$ & 2.93 & hi & 28.97 & ghi & 2.89 & $\mathrm{~d}-\mathrm{h}$ \\
\hline & $\mathbf{H A}_{1}$ & 84.60 & $\mathrm{bc}$ & 3.40 & ijk & 5.48 & $a b$ & 53.82 & $\mathrm{bc}$ & 3.81 & $\mathrm{bc}$ & 36.60 & de & 2.64 & $f-j$ \\
\hline & $\mathbf{H A}_{2}$ & 88.60 & $\mathrm{ab}$ & 3.61 & $\mathrm{~h}-\mathrm{k}$ & 5.55 & $\mathrm{ab}$ & 43.31 & e-h & 3.85 & $\mathrm{ab}$ & 42.01 & $\mathrm{~b}$ & 3.57 & bcd \\
\hline \multirow{6}{*}{ Ceren } & Kontrol & 82.20 & $\mathrm{~cd}$ & 4.61 & def & 3.41 & $\mathrm{ij}$ & 39.83 & $f-i$ & $\underline{\mathbf{2 . 5 8}}$ & $i$ & 37.36 & cde & 2.14 & $\mathrm{ij}$ \\
\hline & Saf su & 84.40 & $\mathrm{bc}$ & 3.99 & $f-j$ & 4.15 & e-h & 39.25 & $f-i$ & 3.17 & efg & 39.69 & bcd & 3.40 & b-e \\
\hline & $\mathbf{G A}_{1}$ & 89.73 & $\mathrm{ab}$ & 5.99 & $\mathrm{ab}$ & 4.43 & $c-f$ & 35.76 & $\mathrm{jk}$ & 2.78 & $\mathrm{ij}$ & 34.72 & ef & 2.76 & $e-i$ \\
\hline & $\mathbf{G A}_{2}$ & 89.53 & $a b$ & $\underline{6.49}$ & $\underline{a}$ & 4.63 & $c-f$ & 41.52 & $e-h$ & 3.23 & efg & 31.11 & fgh & 2.96 & $\mathrm{c}-\mathrm{h}$ \\
\hline & $\mathbf{H A}_{1}$ & 88.87 & $a b$ & 5.53 & $\mathrm{bc}$ & 4.04 & $e-i$ & 36.52 & $\mathrm{ijk}$ & 4.79 & $\mathrm{ab}$ & 32.43 & $\mathrm{fg}$ & 3.05 & $\mathrm{c}-\mathrm{g}$ \\
\hline & $\mathbf{H A}_{2}$ & $\underline{93.80}$ & $\underline{a}$ & 4.19 & fgh & 4.61 & $c-f$ & 46.44 & def & 3.81 & $\mathrm{bc}$ & 39.75 & bcd & 3.69 & $a b c$ \\
\hline \multirow{6}{*}{ Sultan } & Kontrol & $\underline{67.33}$ & $\underline{i}$ & 3.68 & g-k & 3.95 & $e-j$ & 56.28 & $a b$ & 3.59 & $\mathrm{~cd}$ & 51.37 & $\mathrm{a}$ & 3.00 & $\mathrm{c}-\mathrm{h}$ \\
\hline & Saf su & 89.93 & $a b$ & 3.88 & $f-j$ & 4.69 & cde & $\underline{57.60}$ & $\underline{a}$ & $\underline{5.39}$ & $\underline{a}$ & $\underline{54.06}$ & $\underline{a}$ & 4.29 & $\underline{a}$ \\
\hline & $\mathbf{G A}_{1}$ & 82.27 & cd & 5.06 & cde & 4.98 & bcd & 42.95 & e-h & 5.21 & $\mathrm{a}$ & 39.90 & bcd & 2.28 & hij \\
\hline & $\mathbf{G A}_{2}$ & 82.72 & $\mathrm{~cd}$ & 5.65 & $\mathrm{bc}$ & 5.09 & $\mathrm{bc}$ & 45.21 & def & 3.84 & $\mathrm{ab}$ & 41.21 & $\mathrm{bc}$ & 2.44 & $f-j$ \\
\hline & $\mathbf{H A}_{1}$ & 85.47 & $\mathrm{bc}$ & 4.10 & $f-i$ & 5.81 & $\mathrm{a}$ & 38.75 & $\mathrm{ij}$ & 3.34 & def & 37.05 & cde & 2.78 & e- \\
\hline & $\mathbf{H A}_{2}$ & 88.93 & $a b$ & 4.20 & fgh & $\underline{6.05}$ & $\underline{a}$ & 56.16 & $a b$ & 4.88 & $\mathrm{ab}$ & 37.44 & cde & 3.13 & $c-f$ \\
\hline \multirow{6}{*}{ Yerel } & Kontrol & 70.47 & ghi & 3.78 & $f-j$ & $\underline{2.47}$ & $\underline{\boldsymbol{k}}$ & 33.89 & $\mathrm{jk}$ & 2.61 & & 31.32 & fgh & 2.40 & $f-j$ \\
\hline & Saf su & 84.73 & $\mathrm{bc}$ & 4.20 & fgh & 3.53 & hij & 46.93 & def & 4.92 & $\mathrm{a}$ & 41.07 & $\mathrm{bc}$ & 3.88 & $a b$ \\
\hline & $\mathbf{G A}_{1}$ & 72.47 & $f-i$ & 4.94 & cde & 3.63 & $g-j$ & $\underline{25.94}$ & $\underline{l}$ & 2.98 & gh & $\underline{24.53}$ & $\dot{i}$ & 2.32 & $g-j$ \\
\hline & $\mathbf{G A}_{2}$ & 73.27 & fgh & 5.29 & bcd & 3.95 & $e-j$ & 28.35 & 1 & 3.59 & $\mathrm{~cd}$ & 25.85 & $\mathrm{ij}$ & 2.84 & $d-i$ \\
\hline & $\mathbf{H A}_{1}$ & 75.93 & efg & 3.31 & $\mathrm{jk}$ & 4.35 & d-g & 39.60 & $f-i$ & 3.06 & $\mathrm{fg}$ & 29.31 & ghi & 2.39 & $f-j$ \\
\hline & $\mathbf{H A}_{2}$ & 86.07 & $\mathrm{bc}$ & 4.43 & efg & 4.46 & c-f & 36.40 & ijk & 3.13 & $\mathrm{fg}$ & 34.35 & ef & 3.01 & \\
\hline
\end{tabular}

* Her sütunda aynı harfle gösterilen ortalamalar arasında 0.01 önem düzeyine göre fark yoktur. 

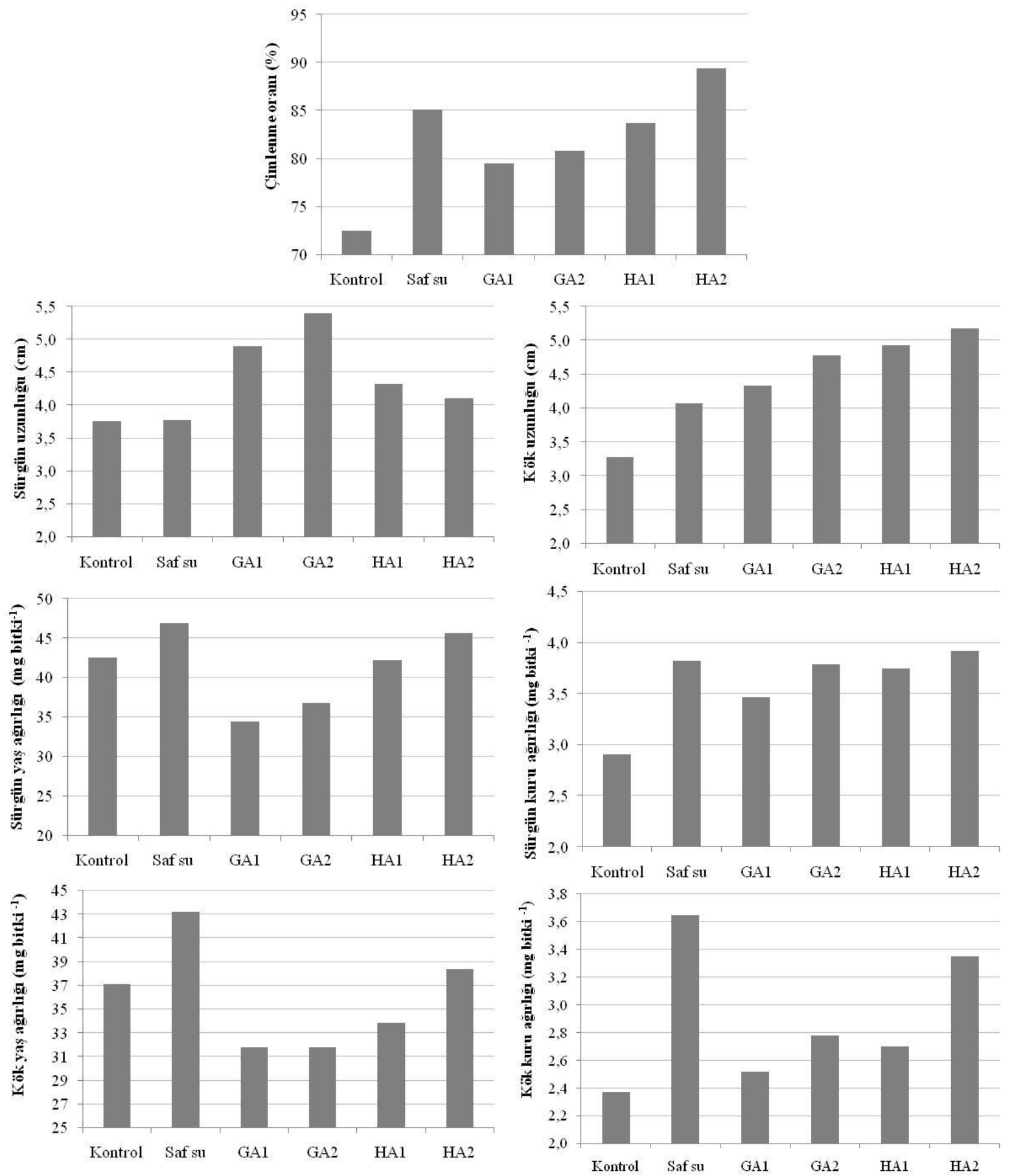

Şekil 1. Mercimek çeşitlerinde tohum ön uygulamalarının incelenen özelliklere etkilere etkileri

\section{IV.SONUÇ}

Türkiye'de başta mercimek olmak üzere yemeklik tane baklagillerin ekim alanı ve üretimi giderek azalmaktadır. Mercimeğin ekim sonrası çıkısın az olması yetiştiriciliğinin azalmasının temel nedenlerindendir. Yetiştiricilikte daha üniform ve hızlı bir çıkışı sağlayarak bitkilerden birim alandan elde edilecek verimi arttırmak amacıyla priming gibi farklı uygulamalara yer verilmektedir. Tohumun çimlenmeye alınmadan önce suda, büyüme düzenleyicileri gibi maddelerde bekletmenin çimlenmeyi olumlu etkilediği bilinmektedir. Sonuç olarak, mercimek çeşitlerine farklı ön uygulamalar yaparak yürüttüğümüz çalışmada uygulanan bütün ön uygulamaların kontrole göre çimlenme oranını arttırdığı belirlenmiş̧ir. Kontrolle kıyaslandığında çimlenme oranında en fazla artış \% 23.2 ile $\mathrm{HA}_{2}$ ve \% 17.3 ile saf su uygulamasından elde edilmiştir. Gibberellik asit 
dozlarının sürgün uzunluğuna, hümik asit dozlarının kök uzunluğuna daha etkili olduğu ve priming uygulamalarının incelenen çimlenme kriterlerine genellikle olumlu etki ettiği belirlenmiştir. Bundan sonraki çalışmalarda bu maddelerin pratikte, yani yetiştirici bazında nasıl uygulanabilir olduğunu ve nelere dikkat edilmesi gerektiği ortaya koymak gerekmektedir. Böylece yetiştiricinin fazla tohum atarak ulaşmaya çalıştı̆ı bitki sıklığını sağlarken, fazla tohum masrafından kurtulmasını sağlamak hedeflenmelidir.

\section{KAYNAKLAR}

[1] FAO, 2017. Statistical Databases, http://faostat.fao.org/site/567/default.aspx\#ancor. (01.07.2019).

[2] TUIK, 2018. Agricultural Statistics database. Turkish Statistical Institute, Ankara, www.tuik.gov.tr $(01.07 .2019)$

[3] Sarker, A., Erskine, W., \& Singh, M. (2003). Regression models for lentil seed and straw yields in Near East. Agri and Forest Meteor, 116: 61-72.

[4] Fischer, R.A., \& Turner, N.C. (1978). Plant productivity in the arid and semiarid zones. Ann Rev Plant Physiol, 29,277-317.

[5] Ghasemi-Golezani, K., Japparpour-Bonyadi, Z., Shafagh-Kolvanagh, J., \& Nikpour-Rashidabad, N. (2013). Effects of water stress and hydro-priming duration on field performance of lentil. International Journal of Farming and Allied Sciences, 2, 922-925.

[6] Ghassemi-Golezani, K., Aliloo, A. A., Valizadeh, M., \& Moghaddam, M. (2008). Effects of hydro and osmo-priming on seed germination and field emergence of lentil (Lens culinaris Medik.). Notulae Botanicae Horti Agrobotanici Cluj-Napoca, 36(1), 29-33.

[7] Finch-Savange, W.E. (2000). Influence of seed quality on crop establishment, growth and yield. In Seed quality: Basic mechanisms and agricultural implications. The Haworth Press, 361-384.

[8] Halmer P. (2004). Methods to improve seed performance in the field. In: Benech- Arnold RL, Sanchez R (eds) Handbook of Seed Physiology Food Product Press, New York, 125-156.

[9] Asgedom, H., \& Becker, M. (2001). Effect of seed priming with nutrient solutions on germination, seedling growth and weed competitiveness of cereals in Eritrea. Margraf Publishers Press, p.282.

[10] Ashraf, M., \& Foolad, M.R. (2005). Pre-sowing seed treatment: A shotgun approach to improve germination, plant growth and crop yield under saline and non-saline conditions. Advances in Agron., 88, 223-271.

[11] Tiryaki, I., Korkmaz, A., Ozbay, N., \& Nas, N.M. (2005). Effect of Priming Supplemented With Plant Growth Regulators On Sorghum (Sorghum Bicolor L. Moench) Seed Germination And Seedling Emergence at Low Temperature. Türkiye VI. Tarla Bitkileri Kongresi. 5-9 Eylül,Antalya.

[12] Bradford, K. J. (1996). Population-based models describing seed dormancy behaviour: implications for experimental design and interpretation. in G. A. Lang, ed. Plant Dormancy: Physiology, Biochemistry and Molecular Biology. Wallingford, U.K., 313-339.

[13] Khan, A.A. (1992). Preplant physiological seed conditioning. Horticultural Reviews, 13, 131-181.

[14] Ruan, S., Xue, Q., \& Tylkowska, K. (2002). Effects of seed priming on germination and health of rice (Oryza sativa L.) seeds. Seed Sci \&Technology, 30: 451-458.

[15] Basra, S.M.A., Afzal, I., Rashid, R.A., \& Farooq, M. (2005). Pre-sowing seed treatments to improve germination and seedling growth in wheat (Triticum aestivum L.). Caderno de Pesquisa Serie Biologia, 17 (1), 155- 164

[16] Abdulrahmani, B., Ghassemi-Golezani, K., Valizadeh, M., \& Feizi-Asl, V. (2007). Seed priming and seedling establishment of barley (Hordeum vulgare L.). J. Food. Agri. Environ., 5 (3\&4),179-184.

[17] Farooq, M., Basra, S,M,A., \& Rehman, H. (2006). Seed priming enhances emergence, yield, and quality of direct-seeded rice. Crop Manag \& Physiol, 3(42-44.35),15-29. 
[18] Ünver, S., Kaya, M., \& Atak, M. (1999). Geçmişten günümüze yemeklik tane baklagiller tarımı. Türk Koop. Ekin Dergisi, 3(7), 40-44.

[19] Rezaei F. (2012). Nohut (Cicer arietinum L.)'ta tohuma ön uygulamanın ilk gelisme, nodülasyon ve tane verimi üzerine etkileri. Doktora Tezi, Ankara Üniversitesi, Fen Bilimleri Enstitüsü, Ankara.

[20] Litterick, A.M., Harrier Wallace, P., Watson, C.A., \& Wood, M. (2004). The rol of uncomposted materials, composts, manures and compost extract in reducing pest and disease incidence and severity in sustainable temperate agricultural and horticultural crop production - a review. Crit. Rev. Plant Sci., 23: 453-479.

[21] Jarošová, M., Klejdus, B., Kováčik, J., Babula, P., \& Hedbavny, J. (2016). Humic acid protects barley against salinity. Acta Physiologiae Plantarum, 38(6), 161.

[22] Çokkızgın, A., (2013). Effects of hydro and osmo-priming on seed vigor of pea (Pisum sativum L). Agriculture, Forestry and Fisheries, 2 (6), 225-228.

[23] Tüfenkçi, S., Türkmen, Ö., Sönmez, F., Erdinc, C., \& Sensoy, S. (2006), "Effects of humic acid doses and application times on the plant growth, nutrient and heavy metal contents of lettuce grown on sewage sludgeapplied soils", Fresenius Environmental Bulletin 15(4), 295-300.

[24] Gulser, F., Sonmez, F., \& Boysan, S. (2010). Effects of calcium nitrate and humic acid on pepper seedling growth under saline condition. Journal of Environmental Biology, 31(5), 873.

[25] Türkmen Ö., Bozkurt, M. A., Yildiz, M., \& Çimrin, K. M. (2004) Effects of nitrogen and humic acid applications on the head weight, nutrient and nitrate contents in lettuce. Advances in Food Science, 26 (2): 59-63.

[26] Westwood, M.N. (1993). Hormones and Growth Regulators, Temperate Zone Pomology: Physiology and Culture. Timber Press Inc, Portland, Oregon, 364-381.

[27] Yamaguchi, S., \& Kamiya, Y. (2002). Gibberellins and light-stimulated seed germination. J. Plant Growth Regul. 20, 369-376.

[28] Halmer, P., \& Bewley J.D. (1984). A physiological perspective on seed vigor testing. Seed Sci: and Tecnol., 8, 562-575.

[29] Rauthan, B.S., \& Schnitzer, M. (1981). Effect of soil fulvic acid on the growth and nutrient content of cucumber (Cucumis sativus) plants. Plant Soil, 63:491-495.

[30] Seçer, M. (1989). Doğal büyüme düzenleyicilerin bitkisel hormonların bitkilerdeki fizyolojik etkileri ve bu alanda yapılan araştırmalar. Derim, 6 (3),109-124.

[31] Iqbal, M. (2004). Inducing Salt tolerance in wheat by pre-sowing seed treatment with plant growth regulators or inorganic salts. Phd. Thesis, University of Agriculture, Institute of Science, Faisalabad, Pakistan.

[32] Avc1, S. (2013). Tuzlu koşullarda bazı güncel buğday çeşitlerinin çimlenme ve bitki gelişimine büyüme düzenleyicilerinin etkisi. Yüksek Lisans Tezi, Süleyman Demirel Üniversitesi, Fen Bilimleri Enstitüsü, Isparta

[33] Kabar, K. (1987). Alleviation of salinity stress by plant growth regulators on seed germination. Journal of Plant Physiology, 128(1-2), 179-183.

[34] Jeyabal, A., \& Kuppuswamy, G. (1998). Effect of seed soaking on seedling vigour, growth and yield of rice. Journal of Agronomy and Crop Science, 180(3), 181-190.

[35] Afzal, I., Basra, S.M.A., Farooq, M., \& Nawaz, A. (2006). Alleviation of salinity stress in spring wheat by hormonal priming with ABA, salicyclic acid and ascorbic acid. Int. J. Agric. Biol., 8: 23-28.

[36] Salehzade, H., Shishvan, M.I., Ghiyasi, M., Forouzin, F., \& Siyahjani, A. (2009). Effect of seed priming on germination and seedling growth of wheat (Triticum aestivum L.). Research Journal of Biological Sciences, 4 (5), 629- 631. 
Özge Doğanay Erbaş Köse, Yusuf Murat Kardeş, Murat Karaer, Zeki Mut/ BŞEÜ Fen Bilimleri, 6. Cilt - Prof. Dr. Fuat SEZGIN Bilim Y11ı Özel Sayıs1, 247-255, 2019

[37] Iqbal, M., \& M. Ashraf. (2005). Changes in growth, photosynthetic capacity and ionic relations in spring wheat (Triticum aestivum L.) due to pre-sowing seed treatments with polyamines. Plant Growth Regulation, 46:19-30.

[38] Kaya, M.D., Okcu, G., Atak, M., Çıkılı, Y., \& Kolsarıcı, Ö. (2006). Seed treatment to overcome salt and drought stress durıng germination in sunflower. Europ.J.Agron., 24(4), 291-295.

[39] Moradi, A., \& Younesi, O. (2009). Effects of osmo-and hydro-priming on seed parameters of grain sorghum (Sorghum bicolor L.). Australian Journal of Basic and Applied Sciences, 3(3), 1696-1700. 